\title{
Assessment of Pulmonary Function Tests among Firefighters in Jerusalem Longitudinal Study
}

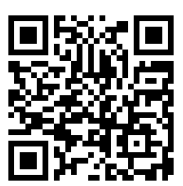

\author{
Mitchnik Ilan, Rokach Ariel*\#, Arish Nissim, Romem Ayal, Azulai Hava, Chen Chen Shuali, Kalak George and Izbicki \\ Gabriel
}

Pulmonary Institute, Shaare Zedek Medical Center, and the Hebrew University Hadassah Medical School, Jerusalem Israel

${ }^{\#}$ Mutual contribution

Received: 偨: December 15, 2018; Published: 制: January 10, 2019

*Corresponding author: Ariel Rokach, Pulmonary Institute, Shaare Zedek Medical Center, Israel

\begin{abstract}
Background: Firefighters are exposed to smoke and airborne toxins with known adverse effects. However, there is a lack of information regarding the respiratory risks they face. Pulmonary tests are not performed regularly on firefighters in Israel. In 2010 many Israeli firefighters were involved in a large-scale forest fire in the Carmel area where they were exposed to heavy smoke burden.

Objectives: We sought to determine whether firefighters are at increased risk for obstructive pulmonary disorders and/or pulmonary function decline.

Methods: We followed a cohort of 153 firefighters for two years. About half of the subjects were involved in the Carmel fire. We evaluated them annually with health questionnaires and spirometry.

Results: We found a 3.9\% prevalence of obstructive disorder. We did not find significant changes in FEV1 nor significant adverse effects of exposure to large forest fires. We found a significant decline in FVC and a 13.1\% prevalence of a restrictive pattern. Smoking was highly prevalent and strongly associated with a decline in pulmonary function.

Conclusion: Firefighters are generally healthy and do not seem to have an increased risk for obstructive disorders. Smoking among firefighters might be associated with accelerated pulmonary function decline. Our findings suggest an increased prevalence of a restrictive pattern; this should be confirmed in further studies.
\end{abstract}

Abbreviations: PM: Particulate Matter; WTC: World Trade Center; PFT: Pulmonary Function Testing; FEV1: Forced Expiratory Volume; FVC: Forced Vital Capacity; CI: Confidence Intervals

\section{Introduction}

Firefighters are exposed to smoke and toxic Particulate Matter (PM) released during fire. Such exposure has adverse effects both acutely and chronically [1]. It is assumed that this population is at an increased risk for respiratory diseases and pulmonary function decline. Until recently, this assumption was not thoroughly studied. Research done after the collapse of the World Trade Center (WTC) shed light on this subject. Rescuers were exposed to high levels of PM and toxins which were released during the collapse $[2,3]$. Following this exposure several respiratory disorders have been described in rescue teams [4-7] and both acute and persistent changes in pulmonary functions were demonstrated [8-11]. However, longitudinal assessment of non-WTC firefighters compared to control subjects did not show greater pulmonary function decline [12]. There is a lack of evidence regarding the respiratory risk's firefighters face. From December 2nd to 5th , 2010, Israel experienced the most severe forest fire in its history. The fire took place in the Carmel area and resulted in the deaths of 43 rescue workers and the hospitalization of others, mainly for acute smoke inhalation and traumatic injury. Consequently, many firefighters were exposed to smoke and other PM in a prolonged and mainly unprotected manner.

Assessment of pulmonary function tests among firefighters in Israel is not regularly performed and therefore little is known about this population. In this research we sought to determine whether firefighters are at an increased risk for obstructive pulmonary disorders and pulmonary function decline. About half of the firefighters in Jerusalem were involved in the Carmel forest fire in 2010. We aimed to compare this group to the firefighters who did 
not participate in the rescue operations at the Carmel forest fire site.

\section{Methods \\ Subjects}

This prospective cohort study was conducted among firefighters employed in Jerusalem from 2014 to 2016. Firefighters were employed by the Jerusalem Firefighting Department during the recruitment period. The Firefighters worked in 5 different stations in the Jerusalem area. The study was approved by our institutional ethical committee. Written informed consent was obtained from all subjects recruited. Baseline Spirometry was done at recruitment. All participants completed a simple questionnaire regarding demographic information, smoking status and basic medical information. Inclusion criteria required a prior history of direct fire exposure at any time during service. This was ascertained via a face-to-face interview conducted with each subject. There were no exclusion criteria for participation in this study.

\section{Procedures}

A research team composed of a Pulmonologist and a pulmonary function technician went to each of the firefighting stations in Jerusalem. All subjects filled out a basic health questionnaire and a follow-up questionnaire at their next visit. All the participants performed a simple Pulmonary Function Testing (PFT) using a Koko Legend II Spirometer. The Spirometer was calibrated at the beginning of each day. Physical examination was performed by the Pulmonologist who also informed the subject about the PFT's results. Smokers were briefly advised regarding smoking cessation. Two follow-up visits were done after one and two years.

\section{Terms and Measures}

Spirometry was done according to the ATS/ERS guidelines [13] and Forced Expiratory Volume in the first second (FEV1) as well as Forced Vital Capacity (FVC) were obtained. In accordance with Gold recommendations [14] FEV1/FVC ratio of less than 0.7 was used to diagnose an obstructive disorder. The severity of the obstructive disorder was defined by the FEV1 predicted percentage. FEV1 higher than $80 \%$ was defined as a mild obstructive disorder, 50 $80 \%$ as a moderate obstruction, $30-50 \%$ as a severe obstruction and values less than $30 \%$ as a very severe obstructive disorder. FVC values of less than $80 \%$ of the predicted value were defined as suggestive of a restrictive pulmonary disorder.

\section{Other Parameters Included}

Weight, height, years of service, smoking habits and respiratory complaints as reported by subjects at every visit. We also asked subjects to report the number of hours they had been exposed to smoking both actively and passively during the last 24 hours before they performed the pulmonary function test. In order to evaluate the level of exposure to fire the subjects were asked whether they were directly involved in the Carmel fire, and the number of fires they had been exposed to in the year prior to each testing. All data was recorded by the team in an Excel worksheet.

\section{Data Analysis}

Averages, standard deviations and absolute prevalence were calculated for all quantitative variables as well as 95\% Confidence Intervals (CI) for all qualitative variables. To evaluate the base prevalence of an obstructive disorder with relation to smoking status and Carmel fire exposure we performed Chi-Square tests and a Fisher exact test. We used Eta and Pearson correlation coefficients to evaluate the strengths of correlations between active service years, participation in the Carmel forest fire, smoking pack years and exposure to smoking 24 hours before the Spirometry, with findings of an obstructive disorder, FEV1 and FVC values. In order to study the longitudinal changes in pulmonary functions with relation to smoking status and level of exposure to fire and smoke, we performed two-way ANOVA and Post-hoc tests. Criteria for acceptance of the research hypothesis for differences: Alpha( $\alpha)$ $=0.05$, one-sided. Criterion for accepting research hypothesis for correlations: Alpha $(\alpha)=0.05$, two-sided. Data analysis was done with IBM SPSS Statistics V20 software.

\section{Results}

Out of one hundred sixty-five firefighters working in the Jerusalem Firefighting Department that agreed to participate in the study, 153 were eligible for this study. Twelve subjects were administrative personnel and were therefore not included in the study. This group was not large enough to use as a control group. The study cohort was comprised mainly of male smokers in their $3^{\text {rd }}$ to $5^{\text {th }}$ decades of life of which about half participated in the Carmel forest fire (Table 1). For the second visit loss to follow-up was $14.4 \%$, while another $13.1 \%$ were not included in the final statistical analysis because a full year had not passed since their first visit. In total, 111 subjects $(72.5 \%)$ completed a second visit after one year. For the third visit, loss to follow-up was $22.2 \%$, while another $34 \%$ were not included in the statistical analysis because a full year had not passed since their second visit. In total, 67 subjects $(43.8 \%)$ completed three visits, after one year and after two years.

\section{Obstructive Disorders and Pulmonary Function Parameters}

An obstructive disorder was found in 6 subjects (3.9\%; $95 \%$ CI, $1.5 \%$ to $8.3 \%$ ). Five of these subjects also reported respiratory complaints but were never diagnosed before. While no subject had a severe obstructive disorder, 2 had a mild disorder and 4 had a moderate disorder. Throughout follow up no other subjects developed an obstructive disorder. All the subjects with an obstructive disorder were active smokers (Figure 1).Among smokers an obstructive disorder was present in 7\% (95\% CI, 2.2\% to $14.9 \%$ ) as opposed to $0 \%$ in those who had never smoked (95\% CI, $0 \%$ to $6.4 \%)$.This difference was not statistically significant $(\mathrm{p}=0.102)$. Four of the subjects with an obstructive disorder participated in the Carmel fire (Figure 1). Of all subjects who participated in the Carmel fire, 5\% were found to have an obstructive disorder $(95 \%$ CI, $1.5 \%$ to $13.1 \%$ ), while $3 \%$ of those who did not participate in the Carmel fire had an obstructive disorder (95\% CI, 0.3\% to 9\%). This difference was also not statistically significant ( $p=0.322)$. A $13.1 \%$ prevalence rate of a restrictive pattern was shown in Table 1. 
Table 1: Baseline study population characteristics.

\begin{tabular}{|c|c|c|}
\hline \multicolumn{3}{|c|}{ Firefighters $(n=153)$} \\
\hline \multicolumn{3}{|c|}{ Gender, $\mathbf{N}(\%)$} \\
\hline Male & 150 & $(98.00)$ \\
\hline Female & 3 & $(2.00)$ \\
\hline \multicolumn{3}{|c|}{ Demographics at Baseline, N (SD) (Min, Max) } \\
\hline Age (years) & 38.26 & $(10.78)(23,67)$ \\
\hline Height $(\mathrm{cm})$ & 176.18 & $(6.72)(159,193)$ \\
\hline Weight (kg) & 81.31 & $(11.59)(55,130)$ \\
\hline BMI (kg/m2) & 26.61 & $(3.65)(19,40)$ \\
\hline \multicolumn{3}{|c|}{ Smoking Status, N (\%) } \\
\hline Never smoked & 46 & $(30.26)$ \\
\hline Smokers (current and former) & 106 & $(69.74)$ \\
\hline \multicolumn{3}{|c|}{ Fire Exposure, $\mathrm{N}(\%)$} \\
\hline Participated in the Carmel fire & 75 & $(49.00)$ \\
\hline Light fire exposure in past year & 112 & $(73.70)$ \\
\hline Heavy fire exposure in past year & 40 & $(26.30)$ \\
\hline \multicolumn{3}{|c|}{ Exposure Characteristics, M (SD) (Min, Max) } \\
\hline Pack years & 10.33 & $(14.75)(0,105)$ \\
\hline Smoking in 24 hours before Spirometry (hours) & 5.42 & $(6.49)(0,24)$ \\
\hline Active service (years) & 11.37 & $(10.69)(0,42)$ \\
\hline \multicolumn{3}{|c|}{ Baseline Spirometry, M (SD) (Min, Max) } \\
\hline FEV1 (L) & 4.00 & $(0.70)(5.77,2.27)$ \\
\hline FEV1 (\% predicted) & 97.99 & $(11.57)(65,126)$ \\
\hline FVC (L) & 4.80 & $(0.77)(2.436 .58)$ \\
\hline FVC $(\%$ predicted $)$ & 95.68 & $(12.14)(51,128)$ \\
\hline \multicolumn{3}{|c|}{ Pulmonary Function Disorders, N (\%) } \\
\hline FEV1/FVC $<0.7$ & 6 & $(3.90)$ \\
\hline $\mathrm{FVC}<80 \%$ & 20 & $(13.10)$ \\
\hline \multicolumn{3}{|c|}{$\mathrm{N}=$ Number; $\mathrm{M}=$ Mean; $\mathrm{SD}=$ Standard Deviation; $\min =$ Minimum; $\max =$ Maximum, $\mathrm{L}=$ Liters. } \\
\hline \multicolumn{3}{|c|}{$\%=$ Refers to valid percentage of question responders. } \\
\hline \multicolumn{3}{|c|}{ "Light Fire Exposure" = less than 3 exposures to forest fires. } \\
\hline \multicolumn{3}{|c|}{ "Heavy Fire Exposure" = 3 or more exposures to forest fires. } \\
\hline
\end{tabular}

Figure 1: Changes in FEV1 (a) and FVC (b) values in liters throughout a two year follow up of the general group: "All subjects"
(Thick Black Line, $\mathrm{n}=67, \mathrm{p}$ for trend $\mathrm{a}=0.078, \mathrm{p}$ for trend b=0.0001) and subgroups: "Smokers" (Solid Triangle, $\mathrm{n}=52$ ) and “Non-
Smokers" (Empty Triangle, $\mathrm{n}=15, \mathrm{p}$ for trend a difference=0.242, $\mathrm{p}$ for trend b difference=0.234), "Involvement in Carmel”
(participated in the Carmel forest fire, Solid Diamond, $\mathrm{n}=41$ ) and “No Involvement in Carmel” (did not participate in the
Carmel forest fire, Empty Diamond, $\mathrm{n}=26, \mathrm{p}$ for trend a difference=0.139, $\mathrm{p}$ for trend b difference=0.320).


We also analyzed the correlation between years of active duty and smoking status with pulmonary function parameters and the presence of an obstructive disorder or a restrictive pattern (Table 2). Lengthier service, heavier smoking and exposure to smoke in proximity to the time of testing showed a mild to moderate correlation with decreased pulmonary function parameters and were statistically significant (Table 2). The highest explained variance $(29.48 \%)$ was between years of active duty and FEV1. All correlations with the presence of an obstructive disorder and a restrictive pattern were significant. The strongest correlation of 0.817 and effect size of 0.67 was for pack years and the presence of an obstructive disorder.

Table 2: Characteristics of correlations between exposures and pulmonary functions and respiratory disorders.

\begin{tabular}{|c|c|c|c|}
\hline Exposure and Measure & Correlation Co-Efficient & Explained Variance & Effect Size \\
\hline \multicolumn{4}{|c|}{ Years in Service and } \\
\hline FEV1 (L) & $-0.543^{* * *}$ & $29.48 \%$ & \\
\hline FEV1 (\% predicted) & -0.133 & $1.76 \%$ & \\
\hline FVC (L) & $-0.416^{* * *}$ & $17.30 \%$ & \\
\hline FVC (\% predicted) & -0.019 & $0.00 \%$ & \\
\hline Obstructive disorder & $0.671^{* * *}$ & & 0.45 \\
\hline Restrictive pattern & $0.694^{* * *}$ & & 0.48 \\
\hline \multicolumn{4}{|c|}{ Pack Years and } \\
\hline FEV1 (L) & $-0.391^{* * *}$ & $15.28 \%$ & \\
\hline FEV1 (\% predicted) & -0.102 & $1.04 \%$ & \\
\hline FVC (L) & -0.053 & $0.28 \%$ & \\
\hline FVC (\% predicted) & +0.009 & $0.00 \%$ & \\
\hline Obstructive disorder & $0.817^{* * *}$ & & 0.67 \\
\hline Restrictive pattern & $0.693^{* * *}$ & & 0.48 \\
\hline \multicolumn{4}{|c|}{ Exposure to Smoke in Last 24 Hours before Spirometry and } \\
\hline FEV1 (L) & $-0.185 *$ & $3.42 \%$ & \\
\hline FEV1 (\% predicted) & $-0.232 * *$ & $5.38 \%$ & \\
\hline FVC (L) & $-0.300 * * *$ & $9.00 \%$ & \\
\hline FVC (\% predicted) & -0.023 & $0.00 \%$ & \\
\hline Obstructive disorder & $0.554^{* * *}$ & & 0.31 \\
\hline Restrictive pattern & $0.386^{* * *}$ & & 0.15 \\
\hline \multicolumn{4}{|c|}{$\begin{array}{l}\text { This table presents the correlation co-efficient between different exposures with measured pulmonary functions, an obstructive disorder and } \\
\text { restrictive pattern as well as the explained variation and effect size if appropriate. }\end{array}$} \\
\hline \multicolumn{4}{|c|}{$\mathrm{L}=$ Liters, $\%$ predicted $=$ percent predict according to age, gender and height. } \\
\hline \multicolumn{4}{|c|}{${ }^{*} \mathrm{p}<.05,{ }^{* *} \mathrm{p}<.01,{ }^{* * *} \mathrm{p}<.001$} \\
\hline
\end{tabular}

\section{Assessment of Changes in Pulmonary Functions}

Changes in FEV1 were statistically insignificant throughout follow up (Figure 1a). The average rate of FEV1 decline in the general group was 20 milliliters per year $(95 \% \mathrm{CI},-50$ to +10 $\mathrm{mL}$ /year). Smokers demonstrated an average FEV1 decline of 30 milliliters per year while non-smokers exhibited an average decline of 10 milliliters per year; this difference in changes (Figure 1a) and rates (Table 3) was statistically insignificant ( $p=0.242, p=0.176$, respectively). The average decline in FEV1 among firefighters Table 3: Rates of changes in pulmonary functions. who had heavy fire exposure was of 30 milliliters per year. This rate was not significantly different from that of those with less fire exposure (40 milliliters per year, $\mathrm{p}=0.908$ ). We found no significant differences in FEV1 changes between those who participated in the Carmel forest fire and those who did not. The general group had statistically significant changes in FVC throughout follow up (Figure 1b ) $(p=0.0001)$ and exhibited an average decline of 110 milliliters per year ( $95 \% \mathrm{CI},-150$ to $-70 \mathrm{~mL} /$ year). Subgroup analysis showed no differences in changes (Figure $1 \mathrm{~b}$ ) and (Table 3 ).

\begin{tabular}{|c|c|c|}
\hline Group & Changes in FEV1 & Changes in FVC \\
\hline All subjects & $-20(95 \% C I,-50$ to +10$)$ & $-110(95 \% C I,-150$ to -70$)$ \\
\hline Smokers; Non-smokers & $-30 ;-10(p=0.176)$ & $-100 ;-120(p=0.340)$ \\
\hline Heavy fire exposure; Light fire exposure & $-30 ;-40(p=0.908)$ & $-120 ;-100(p=0.716)$ \\
\hline Participated in the Carmel fire; Did not participate & $-10 ;-40(p=0.405)$ & $-110 ;-110(p=0.960)$ \\
\hline
\end{tabular}

This table presents the average rates of changes in FEV1 and FVC in milliliters per year after two years of follow up along with their Confidence Interval (CI) or Statistical Significance (p) as appropriate. 


\section{Discussion and Conclusion}

This is the first study to assess changes in pulmonary function among firefighters in Israel. We have found a prevalence of $3.9 \%$ of obstructive disorder in firefighters in Jerusalem. We did not find a statistically significant decline in FEV1, but we did find a significant decline in FVC. No significant differences were found among firefighters with different levels of exposure to fires including the Carmel forest fire. It appears that firefighters in Jerusalem are in general healthy with a low prevalence of obstructive disorders. It also seems the Carmel forest fire did not have an impact on the respiratory health of the firefighters who were involved. Our findings are consistent with those of other researchers. We found that the prevalence of obstructive disorders is lower than that reported in the general population of $10 \%$ [15] and similar to that reported in New York City firefighters [12]. The rate of FEV1 decline ( -20 milliliters per year) is lower than the one measured in the general population (-30 milliliters per year) [16]. It is fair to assume that the reason for these findings is the healthy worker phenomena [17], in which a selection bias causes the exclusion of un-healthy workers who retire from the workplace or are not hired in the first place and the inclusion of healthy workers who continue to work.

Furthermore, it is possible that subjects who did develop a pulmonary disorder left their workplace and therefore our tests found a lower prevalence of obstructive disorders. Our research showed a negative correlation between years of service and FEV1 as well as FVC values (Table 2). This finding suggests that firefighting might be hazardous to the respiratory system leading to diminished pulmonary function parameters. However, we did not discover any findings suggesting long term pulmonary harm following involvement in the Carmel fire nor did we find significant differences between heavy and light fire exposure. This could indicate that forest fire exposure is different from the exposure in the WTC rescue operations. Although it is not possible to diagnose a restrictive lung disorder with simple Spirometry, we did note that the prevalence of a restrictive pattern $(13.1 \%)$ was greater than that of an obstructive disorder. We also found a significant decline in FVC values (Figure 1b). A decline of 110 milliliter per year in FVC is of concern and should prompt continued follow up. Similar findings have been described in large studies among firefighters in the USA [8-12]. A possible explanation for this is the acquirement of restrictive lung diseases. For this reason, we believe that it is important to address these findings and conduct further research to identify possible restrictive lung diseases in firefighters, by doing serial lung volume measurements and follow up chest X-ray.

Although we did not find a significant difference in the prevalence of obstructive disorder between smokers and non-smokers our findings suggest that smoking affects pulmonary functions more than fire exposure (Table 2). It is likely that we failed to demonstrate a significant difference due to our small sample size. Regardless, it is important to note that $23.8 \%$ of smoking firefighters quit smoking following our brief smoking cessation counselling. This finding suggests that pulmonary function screening (Spirometry) coupled with a brief consultation to stop smoking is a crucial tool in smoking cessation, especially among firefighters. Another finding was a negative correlation between smoking immediately prior to testing and pulmonary functions (Table 2). This adds to the results of other researchers [18] about the immediate effect of smoking on pulmonary functions. This effect should be taken into consideration when performing Spirometry. Another incidental finding included the fact that at least two of the 56 subjects who were lost to follow up acquired neoplastic diseases. One had lung cancer and the other had lymphoma. Since we did not manage to contact all of the subjects who dropped out, there is a possibility that the incidence of these diseases is greater and could possibly require further evaluation in firefighters. Our study has several limitations, the most important of which is the sample size during continued visits. Three main factors influenced the loss to follow up. First, some firefighters were relocated to other cities. Second, developments in the security situation in Jerusalem prevented us from reaching subjects in a remote area of the city. Third, some of the subjects were recruited during 2015 and 2016 and could not be included in the follow up after one or two years (a full year had not passed since their first visit).

Another important limitation is that the time frame we followed our subjects was short compared to other researches. It is likely that more than 3 annual visits are required to gain a better understanding of the changes in pulmonary function parameters. In summary, we found a low prevalence of obstructive disorders in firefighters as well as an insignificant decline in FEV1 most likely due to the healthy worker phenomenon. We weren't able to show any hazardous effects related to the Carmel fire similar to those reported among the WTC rescue workers. This is probably due to the different type of exposure in forest fires. We did find a concerning decline in FVC and the emergence of a restrictive pattern in lung function studies which requires further evaluation for restrictive lung disorders. Our study suggests that firefighters are not at increased risk of obstructive disorders but could be at risk for restrictive lung disorders. We also demonstrated that a brief consultation regarding smoking cessation coupled with pulmonary function test led to a smoking cessation rate of $23.8 \%$. Further follow up and studies are required to evaluate the respiratory risks firefighters face.

\section{Acknowledgement}

The authors wish to thank Dr. Eric Amster for his initial contribution of the health questionnaires used in this research.

\section{References}

1. Dockrey DW, Pope III A, Spengler JD, Spengler JD, Ware JH, et al. (1993) An association between air pollution and mortality in six US cities. N Eng J Med 329(24): 1753-1759.

2. McGee J, Chen L, Cohen M, Glen R Chee, Colette M Prophete, et al. (2002) Chemical analysis of World Trade Center fine particulate matter for use in toxicologic assessment. Environ Health Perspect 111(7): 972-980.

3. Lioy P, Weisel C, Millette J, Steven Eisenreich, Daniel Vallero, et al. (2002) Characterization of the dust/smoke aerosol that settled east of the World Trade Center (WTC) in lower Manhattan after the collapse of the WTC 11 September 2001. Environ Health Perspect 110(7): 703-714.

4. Banauch G, Alleyne D, Sanchez R, Olender K, Cohen HW, et al. (2003) Persistant hyperreactivity and reactive airway dysfunction in fire 
fighters at the World Trade Center. Am J Respir Crit Care Med 168(1): 54-62.

5. Banauch G, Dhala A, Prezant D (2005) Pulmonary disease in rescue workers at the World Trade Center site. Curr Opin Pulm Med 11(2): 160168.

6. Banauch GI, Dhala A, Alleyne D, Alva R, Santhyadka G, et al. (2005) Bronchial hyperreactivity and other inhalation lung injuries in rescue/ recovery workers after the World Trade Center collapse. Crit Care Med 33(1 Suppl): 102-106.

7. Izbicki G, Chavko R, Banauch G, Weiden MD, Berger KI, et al. (2007) World Trade Center "sarcoid-like" granulomatous pulmonary disease in New York city Fire Department rescue workers. Chest 131(5): 14141423.

8. Banauch GI, Hall C, Weiden M, Cohen HW, Aldrich TK, et al. (2006) Pulmonary function after exposure to the World Trade Center collapse in the New York city Fire Department. Am J Respir Crit Care Med 174(3): 312-319.

9. Aldrich TK, Gustave J, Hall CB, Cohen HW, Webber MP, et al. (2010) Lung function in rescue workers at the World Trade Center after 7 years. N Eng J Med 362(14): 1263-1272.

10. Skloot G, Schechter CB, Herbert R, Moline JM, Levin SM, et al. (2009) Longitudinal assessment of spirometry in the World Trade Center medical monitoring program. Chest 135(2): 492-498.

11. Herbert R, Moline J, Skloot G, Metzger K, Baron S, et al. (2006) The World Trade Center disaster and the health of workers: Five-year assessment of

ISSN: 2574-1241

DOI: $10.26717 / B J S T R .2019 .13 .002344$

Rokach Ariel. Biomed J Sci \& Tech Res

This work is licensed under Creative

Commons Attribution 4.0 License

Submission Link: https://biomedres.us/submit-manuscript.php a unique Medical Screening Program. Environ Health Perspect 114(12): 1853-1858.

12. Aldrich TK, Ye F, Hall CB, Hillel W Cohen, Michael Dinkels, et al. (2013) Longitudinal Pulmonary Function in Newly Hired, Non-World Trade Center-Exposed Fire Department City of New York Firefighters. Chest 143(3): 791-797.

13. Miller MR, Hankinson J, Brusasco V, Burgos F, Casaburi R, et al. (2005) ATS/ERS Task Force: Standardisation of Lung Function Testing. Eur Respir J 26: 319-338.

14. (2017) From the Global Strategy for the Diagnosis, Management and Prevention of COPD, Global Initiative for Chronic Obstructive Lung Disease (GOLD).

15. Buist AS, McBurnie MA, Vollmer WM, Burney P, Mannino DM, et al. (2007) International variation in the prevalence of COPD (the BOLD Study): A population-based prevalence study. Lancet 370(9589): 741-750.

16. Kerstjens HA, Rijcken B, Schouten JP, Postma DS (1997) Decline of FEV1 by age and smoking status: facts, figures, and fallacies. Thorax 52(9): 820-827.

17. Li CY, Sung FC (1999) A review of the healthy worker effect in occupational epidemiology. Occup Med 49(4): 225-229.

18. Flouris AD, Metsios GS, Carrillo AE, Gourgoulianis K, Kiropoulos T, et al. (2009) Acute and short-term effects of secondhand smoke on lung function and cytokine production. Am J Respir Crit Care Med 179(11): 1029-1033.

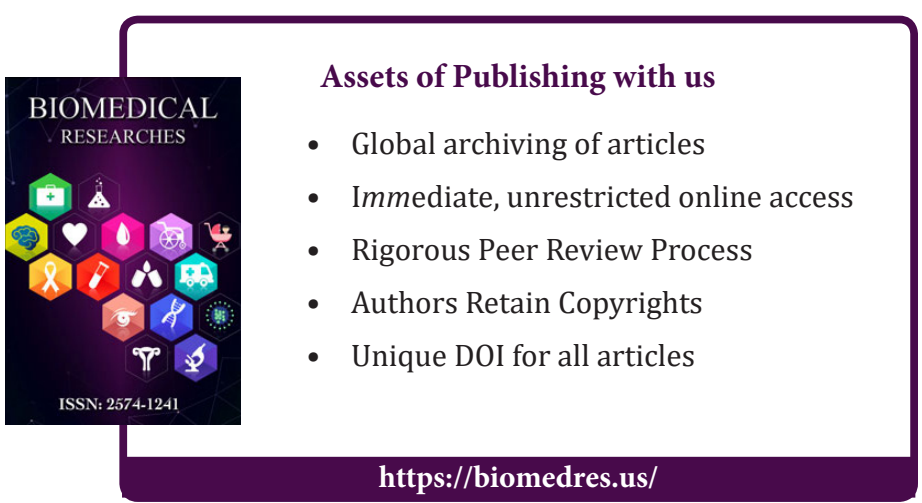

